TITLE:

\title{
Morphogenesis of the Spleen During the Human Embryonic Period
}

\section{$\operatorname{AUTHOR}(\mathrm{S}):$}

Endo, Aya; Ueno, Saki; Yamada, Shigehito; Uwabe, Chigako; Takakuwa, Tetsuya

\section{CITATION:}

Endo, Aya ... [et al]. Morphogenesis of the Spleen During the Human Embryonic Period. The Anatomical Record 2015, 298(8): 820-826

\section{ISSUE DATE:}

2015-05

URL:

http://hdl.handle.net/2433/216676

\section{RIGHT:}

This is the accepted version of the following article: [Endo, A., Ueno, S., Yamada, S., Uwabe, C. and Takakuwa, T. (2015), Morphogenesis of the Spleen During the Human Embryonic Period. Anat Rec, 298: 820-826. doi: 10.1002/ar.23099], which has been published in final form at http://dx.doi.org/10.1002/ar.23099. This article may be used for noncommercial purposes in accordance with Wiley Terms and Conditions for Self-Archiving.; The full-text file will be made open to the public on 19 April 2016 in accordance with publisher's 'Terms and Conditions for Self-Archiving'.; This is not the published version. Please cite only the published version.; この論文は出版社版でありません。引用の際には出版社 版をご確認ご利用ください。 
Morphogenesis of the spleen during the human embryonic period

\section{Aya Endo', Saki Ueno', Shigehito Yamada', 2, Chigako Uwabe ${ }^{2}$, Tetsuya}

Takakuwa ${ }^{1}$

${ }^{1}$ Human Health Science, ${ }^{2}$ Congenital Anomaly Research Center, Graduate School of Medicine, Kyoto University, Sakyo-ku Shogoin Kawahara-cyo 53, Kyoto 606-8507, Japan

Grant sponsors: Japan Society for the Promotion of Science and BIRD of the Japan Science and Technology Agency; Grant numbers: 22591199, 24119002, and 25461642.

Running title: Embryonic morphogenesis of the spleen

Corresponding author: Dr. Tetsuya Takakuwa

Human Health Science, Graduate School of Medicine, Kyoto University

606-8507, Sakyo-ku Shogoin Kawahara-cyo 53, Kyoto, Japan

E-mail: tez@hs.med.kyoto-u.ac.jp

TEL/FAX; +81-75-751-3931 


\section{Abstract}

We aimed to observe morphological changes in the spleen from the emergence of the primordium to the end of the embryonic period by using histological serial sections of 228 samples. Between Carnegie stages (CSs) 14 and 17, the spleen was usually recognized as a bulge in the dorsal mesogastrium (DM), and after CS 20, the spleen became apparent. Intrasplenic folds were observed later. A high-density area was first recognized in 6 of the 58 cases at CS 16 and in all cases examined after CS 18. The spleen was recognized neither as a bulge nor as a high-density area at CS 13. The mesothelium was pseudostratified until CS 16 and was replaced with high columnar cells and then with low columnar cells. The basement membrane was obvious after CS 17 . The mesenchymal cells differentiated from cells in the DM, and sinus formation started at CS 20. Hematopoietic cells were detected after CS 18. The vessels were observed at CS 14 in the DM. Hilus formation was observed after CS 20. The parallel entries of the arteries and veins were observed at CS 23. The rate of increase in spleen length in relation to that of stomach length along the cranial-caudal direction was $0.51 \pm 0.11$, which remained constant during CSs 19 and 23, indicating that their growths were similar. These data may help to better understand the development of normal human embryos and to detect abnormal embryos in the early stages of development.

Key Words: spleen, dorsal mesogastrium, human embryo, morphogenesis 


\section{Introduction}

The spleen is characterized as a bulge in the dorsal mesogastrium (DM) in a fiveweek embryo or approximately $8 \mathrm{~mm}$ of crown-rump length (Ono, 1929; Holyoke, 1936). The developmental process of the spleen can be divided into two stages (Ono, 1929; Weiss, 1973; Weiss and Chen, 1974). During the first stage (up to the $14^{\text {th }}$ week of gestation), the spleen primordium has a mesenchymal character with primary vascular reticulum (Weiss, 1973; Vellguth, 1985). In the latter stage, the red and white pulp-the spleen's architecture-develops after the development of the primordium.

Few histological studies have evaluated the human embryonic spleen according to Carnegie stage (CS), because the aforementioned studies were published before the CSs were established. One description of the embryology of the spleen involved the famous atlas of Gasser (1975) that explained that the development includes four embryos corresponding to five, six, seven, and eight weeks of development, respectively (i.e., CS $13,16,19$, and 23 , respectively) on gross views, but this did not include the detailed histology. At first, the spleen primordium was indicated in the DM of the transverse histological section in a CS 13 embryo (Carnegie Embryo 8066), as cited by O'Rahilly and Müller (1987) and described as follows: "the splenic primordium has been identified as early as stage 13." Another histological study of the spleen in 30 human embryos during CSs 17-23 was reported by Merida-Velasco et al. (1989), which revealed that the splenic primordium is composed of mesenchymal cells and a number of cells that are similar in appearance to lymphoid elements. They detected vessels in the spleen after CS 19.

We aimed to observe morphological changes in the spleen from the emergence of the primordium to the end of the embryonic period by using histological serial sections. Additionally, the growth of the spleen was compared with that of the stomach.

\section{Materials and Methods}




\section{Human embryo specimens}

Approximately 44,000 human embryos comprising the Kyoto Collection, which are collected and stored at the Congenital Anomaly Research Center of Kyoto University (Nishimura et al., 1968; Shiota, 1991; Yamada et al., 2004). In most cases, pregnancy was terminated during the first trimester for socioeconomic reasons under the Maternity Protection Law of Japan. Approximately $20 \%$ of the specimens were undamaged, wellpreserved embryos. When the aborted embryos were brought to the laboratory, they were measured, examined, and staged using the criteria provided by O'Rahilly and Müller (1987). Approximately 500 well-preserved human embryos, diagnosed as externally normal from CSs 13-23, were subjected to histological serial sections.

We included 228 samples consisting of 5-58 samples for each stage, which were selected for macroscopic analysis, and 3-7 samples for each stage were selected for microscopic analysis.

\section{Histological observations}

Histological serial sections stained with hematoxylin and eosin (HE) were observed macroscopically and microscopically by two authors (A.E. and T.T.).

For macroscopic observations, the histological serial sections were digitized using a film scanner (DiMAGE Scan Multi PRO AF-5000, Konica Minolta, Tokyo, Japan). The data were magnified onto a computer display, and the findings at the DM were categorized as follows: 1) The spleen was categorized as (a) a separate segment in the DM, (b) as a bulge in the DM, or (c) not recognizable; and 2) The spleen was recognized as a) a high-density area or b) not recognizable. A bulge (+) was defined when $>80 \%$ of the spleen had separated from the edge of the DM. 
The following three aspects were observed while using microscopic analysis: the mesothelium type, the vascular system (i.e., formation of the hilus and sinus), and the mesenchymal components, including the mesenchymal cells and other cell components.

\section{Position, length, and three-dimensional reconstruction of the spleen}

The digitized histological serial sections were applied to three-dimensional reconstruction. Three-dimensional images of the spleen and stomach were computationally reconstructed and morphometrically observed using Amira ${ }^{\mathrm{TM}}$ software, version 5.4.0 (Visage Imaging, Berlin, Germany). The lengths of the spleen and stomach along the cranial-caudal direction were measured by transverse section of the embryos.

This study was approved by the Committee of Medical Ethics of Kyoto University Graduate School of Medicine, Kyoto, Japan (E986).

\section{Results}

\section{Macroscopic findings}

In most cases, the spleen was recognized as a bulge in the DM between CSs 14 and 17 (Fig. 1, Table 1). The spleen was apparent as a segmented area after CS 20. Intrasplenic folds were observed occasionally at CS 20 and during the later stages (black arrow in Fig.1, CS 23). A high-density area was first recognized in 6 of the 58 cases at CS 16 and then in all cases after CS 18. The spleen was neither recognized as a bulge nor high-density area in all of the 22 cases at CS 13.

\section{Microscopic findings}

The bulge in the DM was detectable using the macroscopic view after CS 14, and we observed the bulge microscopically. 
The mesothelium consisted of only pseudostratified mesothelium between CSs 13 and 15 (arrow in Fig. 2). The border between the mesothelium and mesenchymal cells was ambiguous. Initially, the border between the coelomic epithelium and the mesenchyme of the DM was ambiguous. The cavity within the endometrium that may differentiate into splenic vessels or their derivatives were already observed at the center of the DM at CS 14 (arrowhead in Fig. 2A) and near the mesothelium at the bulge at CS 15 (arrowhead in Fig. 2B). The mesenchymal cells in the DM were homogenous, and no obvious mass indicating the spleen primordium was yet recognized at CSs 14 and 15 .

The bulge underlying the spleen primordium (red rectangle in Fig. $3 \mathrm{~A}$ ) and the dorsal pancreatic duct was observed in the DM at CS 16 with lower magnification. The mesenchymal cells in the spleen primordium and dorsal pancreas were not clearly separated. The mesothelium consisted of pseudostratified cells (arrow in Fig. 3B). The border between the mesothelium and the mesenchymal cells was irregular but distinct, as it was seen as a light zone between the peripheral nuclear stratum and the mesenchyme. The mesenchymal cells at the bulge became highly dense with scarce cytoplasm and irregularly ovoid nuclei and scattered chromatin in 6 of 58 cases at CS 16, though the border of the DM was still not clear. The small cells with condensed nuclei probably hematopoietic cells were observed occasionally.

Several histological changes were detected during CSs 17 and 19. The foldings that separate the spleen from the DM were observed at CS 18 and CS 19 (red arrow head in Fig. 3D-E). The mesothelium changed from a mixture of pseudostratified and high columnar cells to cuboid and/or low columnar cells (arrows in Fig. 3C-E). The mesothelium became sharply cut off from the underlying tissue, indicating the presence of a definite basement membrane. The border of the DM became clear gradually. The mesenchymal cells of the spleen become highly dense, and the short spindle, stellate, 
and/or fusiform with irregularly ovoid nuclei showed scattered chromatin. Small cells with condensed nuclei were occasionally present. Several other types of hematopoietic cells that were not identified were also detected. The cavity within the endometrium was observed in the DM and spleen (* in Fig. 3C-E).

After CS 20, the mesenchymal cells in the spleen and dorsal pancreas were clearly separated by cell density and folding ( ${ }^{* *}$ in Fig. 3G). Intrasplenic folding was observed at CS 21 (red arrow, Fig. 3G). The entries of the branch of the splenic vessels were noted; these entries may form the hilus at a later stage (blue arrow head, Fig. 3F-G). The vessels within the endometrium were detected in the spleen ( ${ }^{*}$ and black arrow head, Fig. 3F-G). Intercellular spaces were present throughout the histological specimen, the pattern formation of the cells was initiated at CS 20, and sinusoids of the spleen's mesenchymal cells formed in the later stages. Small cells with condensed nuclei, which probably were hematopoietic lineage cells, were observed in the capillary and intercellular spaces. The mesothelium consisted of low columnar cells at CSs 20 and 21.

The spleen could be clearly differentiated from the DM as deep folds and small intrasplenic folds (a feature of the adult spleen) (Fig. 4). These mesothelial cells then became progressively flattened, and the basement membrane became apparent at CS 22. Hematopoietic cells with condensed nuclei were observed in the intercellular spaces throughout the spleen.

The entries of several branches of the splenic vessels were detected at CS 23, forming the hilus (arrow head, Fig. 4). Two types of parallel vessels were recognized at CS 23 (red and blue arrow heads, Fig. 4C). One was surrounded with a mesenchymal sheath, while the other with a layer of simple squamous endothelial cells. The former may have been arteries and the latter may have been veins. Capsule formations were not observed until CS 23. 


\section{Location and three-dimensional reconstruction of the spleen}

The location of the spleen was estimated along the cranial-caudal direction using the serial transverse section. The spleen and stomach were reconstructed at CSs 17 and 19 (Fig. 5).

The spleen was very thin and curved, surrounding the stomach at CSs 17 and 19. The spleen was located relative to the stomach. Most of the spleen was located between the gastric cardia and at the most caudal point of the stomach between CSs 19 and 23. The rate of increase in spleen length in relation to that in stomach length, along the cranialcaudal direction, was $0.51 \pm 0.11$, and it remained constant during CSs 19 and 23, indicating that their growth rates were similar.

\section{Discussion}

We described morphological features of the human spleen during CSs 13 and 23. The histological features according to the CS are summarized in Figure 6. It was difficult to confirm the spleen primordium at CS 13 in all cases examined macroscopically and microscopically. The broadening and rotation of the stomach primordium and the deviation of the DM was limited at CS 13. A mass or bulge in the DM was not detectable in our study; however, previous literature reports have shown otherwise (Gasser, 1975; O'Rahilly and Müller 1987). The web atlas on the virtual human embryo has been recently disclosed, in which serial sections of human embryos between CSs 2 and 23 were included (Gasser, 2014). The spleen primordium was first indicated at CS 14 and 15 , while the spleen was recognized after CS 16 in our study, which is consistent with that in the web atlas. Merida-Velasco et al. (1989) detected vessels in the spleen after CS 19, while our study showed the presence of vessels in the DM before the appearance 
of the spleen or its primordium. Small clefts were observed in the spleen at CS 16, and larger vessels entering from the DM into the spleen appeared after CS 20. Those entries formed the spleen's hilus. The present observation was consistent with that of a previous study by Ono (1929) who observed narrow clefts in the mesenchyme, except during the very early embryonic periods; they also observed blood vessels during the 6th and 7th week of fertilization. The connection between the clefts and the larger vessels was not clear in our study, though they showed very similar characteristics. After the opening of the arteries and veins into the mesenchymal meshwork, open circulation may develop in the spleen primordium at this early developmental stage (Ono, 1929). Ono (1929) described that the main vessels of the spleen are established and are present by the 8th week of fertilization.

In the present study, the majority of the cells were mesenchymal, and the remaining cells looked like hematopoietic cell populations. Several types of cells were recognized in these cell populations after CS 19. It was difficult to identify the lineage using hematoxylin and eosin microscopic findings. Djaldetti (1979) demonstrated the presence of hemocytoblasts, proerythroblasts, and megakaryocyte precursors between the mesenchymal cells from the 6th to 7th week of fertilization using electron microscopy, suggesting that hemopoiesis in the embryonic spleen is an extravascular process (Djaldetti M, 1979). Zamboni and Westin (1964) identified blood, and hematopoietic macrophages around the 16th week of fertilization. Those cells are possible candidates for the several types of cells that we were not able to identify in our study.

We found that the ratio of the spleen's length to the stomach's length along the cranial-caudal direction was almost constant (approximately 0.5). Kaigai et al. (2014) reported that the greater and lesser curvature of the stomach grows 1.79 and 1.91 times 
during CSs 19 and 23, respectively. Thus, the spleen may grow at similar rate as the stomach.

A recent study indicated that the morphogenesis of mouse spleen begins bilaterally and posteriorly to the stomach, after which the splenic precursors grow preferentially leftward. Spleen cells may move from the posterior mesenchyme, along the left side of the stomach, and distinctly move close to the adjacent stomach mesenchyme (Asayesh, 2006; Zaret, 2008; Brendolan, 2007; Burn et al., 2008). Several experimental studies in mice have indicated genes are required for spleen development. Sf1 null mice showed impaired spleen development-small and maldeveloped spleens_-but not complete asplenia (Morohashi et al., 1999). Tlx1 (also known as Hox11) null mice exhibited isolated asplenia without other abnormalities (Roberts et al., 1994). Recently, the $P b x / N k x 2-5 / p 15$ regulatory module were determined to be essential for spleen development (Burn et al., 2008; Koss et al., 2012), and genetic studies disclosed the mutations in patients with congenital asplenia, which correspond to the aforementioned experimental studies. Koss et al. (2012) identified a heterozygous missense mutation in NKX2-5, which reduced transactivation. Zangen et al. (2014) identified a recessive mutation within SF1 in a child with both severe $46, \mathrm{XY}$-disorder of sexual development and asplenia. They indicated that $\underline{S F 1}$ was required for spleen development in humans via the transactivation of TLX1. Conversely, Bolze et al. (2013) identified heterozygous mutations in RPSA in patients with isolated congenital asplenia, which was not known to be involved in the spleen development of mice (Koss et al., 2012; Brendolan, 2007). Furthermore, heterozygosity for a null Rpsa allele in mice was not associated with isolated congenital asplenia. Further study is needed to disclose the underlying mechanisms that connect RPSA with spleen development in humans. 
The morphological analysis in our study was limited with HE staining because of the few available samples. However, it may be necessary to use molecular markers such as the $P b x / N k x 2-5 / p 15$ regulatory module and $T L X 1$ transcription factors in human samples so that the conditions are similar to those used in mouse models; this may provide valuable information on the mechanisms underlying the development of mammalian spleen and the etiology of congenital asplenia.

Our study provides data on stage-by-stage morphological changes in the spleen from the emergence of the primordium to the end of the embryonic period by using histological serial sections. These data may help to better understand the development of normal human embryos and to detect abnormal embryos at early stages of development. This may provide insight into future studies on congenital anomalies related to spleenrelated complications such as congenital asplenia and polysplenia. 


\section{References}

Asayesh A, Sharpe J, Watson RP, Hecksher-Sørensen J, Hastie ND, Hill RE, Ahlgren U. 2006. Spleen versus pancreas: strict control of organ interrelationship revealed by analyses of Bapx1-/- mice. Genes Dev 20:2208-2213.

Bolze A, Mahlaoui N, Byun M, Turner B, Trede N, Ellis SR, Abhyankar A, Itan Y, Patin E, Brebner S, Sackstein P, Puel A, Picard C, Abel L, Quintana-Murci L, Faust SN, Williams AP, Baretto R, Duddridge M, Kini U, Pollard AJ, Gaud C, Frange P, Orbach D, Emile JF, Stephan JL, Sorensen R, Plebani A, Hammarstrom L, Conley ME, Selleri L, Casanova JL. 2013. Ribosomal protein SA haploinsufficiency in humans with isolated congenital asplenia. Science 340:976-978.

Brendolan A, Rosado MM, Carsetti R, Selleri L, Dear TN. 2007. Development and function of the mammalian spleen. Bioessays 29:166-177.

Burn SF, Boot MJ, de Angelis C, Doohan R, Arques CG, Torres M, Hill RE. 2008. The dynamics of spleen morphogenesis. Dev Biol 318:303-311.

Djaldetti M. 1979. Hemopoietic events in human embryonic spleens at early gestational stages. Biol Neonate 36:133-144.

Gasser RF. 1975 Atlas of Human Embryos, 1st ed. Hagerstown: Harper and Row.

Gasser RF, Cork RJ, Stillwell BJ, McWilliams DT. 2014. Rebirth of human embryology. Dev Dyn 243:621-628.

Holyoke EA. 1936

The role of the primitive mesothelium in the development of the mammalian spleen. Anat Rec 49 243-250.

Koss M, Bolze A, Brendolan A, Saggese M, Capellini TD, Bojilova E, Boisson B, Prall OW, Elliott DA, Solloway M, Lenti E, Hidaka C, Chang CP, Mahlaoui N, Harvey RP, Casanova JL, Selleri L. 2012. Congenital asplenia in mice and humans with mutations in a Pbx/Nkx2-5/p15 module. Dev Cell 22:913-926. 
Kaigai N, Nako A, Yamada S, Uwabe C, Kose K, Takakuwa T. 2014. Morphogenesis and three-dimensional movement of the stomach during the human embryonic period. Anat Rec (Hoboken) 297:791-797.

Merida-Velasco JA, Sanchez-Montesinos I, Espin-Ferra J, Garcia-Garcia JD. 1989. Histogenesis of the spleen in the human embryo in O'Rahilly's stages 17 to 23 . Arch Anat Histol Embryol 72:97-104.

Morohashi K, Tsuboi-Asai H, Matsushita S, Suda M, Nakashima M, Sasano H, Hataba Y, Li CL, Fukata J, Irie J, Watanabe T, Nagura H, Li E. 1999. Structural and functional abnormalities in the spleen of an mFtz-F1 gene-disrupted mouse. Blood 93:1586-1594.

Nishimura H, Takano K, Tanimura T, Yasuda M. 1968. Normal and abnormal development of human embryos: first report of the analysis of 1,213 intact embryos. Teratology 1:281-290.

O'Rahilly R, Müller F. 1987. Developmental stages in human embryos: including a revision of Streeter's Horizons and a survey of the Carnegie Collection. Washington, D.C.: Carnegie Institution of Washington.

Ono K. 1929 Untersuchungen ueber die Entwicklung der menschlichen Milz. Z f Zellforschung u mikr Anatomie 10:573-603.

Roberts CW, Shutter JR, Korsmeyer SJ. 1994. Hox11 controls the genesis of the spleen. Nature 368:747-749.

Sabin FR. 1912 The development of the spleen. In: Keibel F, Mall FP, editors. Manual of Human Embryology. Philadelphia: Lippincott. p 745-751.

Shiota K. 1991. Development and intrauterine fate of normal and abnormal human conceptuses. Congenit Anom Kyoto 31:67-80. 
Thiel GA, Downey H. 1921. The development of the mammalian spleen, with special reference to its hematopoietic activity. Am J Anatomy 28:279-339.

Vellguth S, von Gaudecker B, Müller-Hermelink HK. 1985. The development of the human spleen. Ultrastructural studies in fetuses from the 14th to 24th week of gestation. Cell Tissue Res 242:579-592.

Weiss L. 1973. The development of the primary vascular reticulum in the spleen of human fetuses (38- to 57-mm crown-rump length). Am J Anat 136:315-337.

Weiss L, Chen LT. 1974. The differentiation of white pulp and red pulp in the spleen of human fetuses (72-145 mm crown-rump lenght). Am J Anat 141:393-413.

Yamada S, Uwabe C, Fujii S, Shiota K. 2004. Phenotypic variability in human embryonic holoprosencephaly in the Kyoto Collection. Birth Defects Res A Clin Mol Teratol 70:495508.

Zamboni L, Westin B. 1964. The ultrastructure of the human fetal spleen. I. One type of mesenchymal cell in the early stages of development of the spleen. J Ultrastruct Res 11:469-493.

Zangen D, Kaufman Y, Banne E, Weinberg-Shukron A, Abulibdeh A, Garfinkel BP, Dweik D, Kanaan M, Camats N, Flück C, Renbaum P, Levy-Lahad E. 2014. Testicular differentiation factor SF-1 is required for human spleen development. J Clin Invest 124:2071-2075.

Zaret KS. 2008. Genetic programming of liver and pancreas progenitors: lessons for stem-cell differentiation. Nat Rev Genet 9:329-340. 


\section{Figure Legends}

Figure 1. Macroscopic view of the dorsal mesogastrium showing the presence of the spleen or its primordium at Carnegie stages 14, 16, 20, and 23.

*, spleen (primordium); St, stomach; red arrow, segmentation by the folds; black arrow, intrahepatic folds

Figure 2 Histology of the dorsal mesogastrium and the underlying splenic primordium at Carnegie stages 14 (A) and 15 (B). Hematoxylin and eosin staining, x400.

Arrow, pseudostratified mesothelium; arrowhead, splenic vessels and their derivative in the dorsal mesogastrium. DM, dorsal mesogastrium; LS, lesser sac; Me; mesonephric duct; PC, peritoneal cavity; St, stomach

Figure 3 Histology of the spleen (primordium) between Carnegie stages (CS) 16 and 22. Hematoxylin and eosin staining.

(A, B) The dorsal mesogastrium and the underlying splenic primordium at CS $16(\mathrm{x} 100)$. (B) A higher magnification (x400) of the bulge of the dorsal mesogastrium indicated by a square $(A)$.

(C-E) Histology of the spleen at CSs 17 (C), 18 (D), $19(\mathrm{E}), 20(\mathrm{~F})$, and 21 (G) (x400). Gross view (x40) of the dorsal mesogastrium (inset of $F$ ) indicated in the magnified area. Arrow, pseudostratified mesothelium; black arrow head and *, splenic vessels and their derivative in the dorsal mesogastrium or intracellular space; red arrow head and ${ }^{* *}$, segmentation of the spleen from the dorsal mesogastrium by folding; blue arrow head, veins. 
Ao, aorta; DM, dorsal mesogastrium; DP, dorsal pancreas; Ge, genital bulging; Li, liver;

LS, lesser sac; Me, mesonephric duct; PC, peritoneal cavity; St, stomach; Sp, spleen. The high-density area represents mesenchymal cells.

Figure 4 Histology of the spleen at Carnegie stages 22 and 23.

(A) CS22, Hematoxylin and eosin, x200; (B) CS 23 at the lower magnification hematoxylin and eosin, $x 100$; (C) Higher magnification (x400) of the arteries and veins in the dorsal mesogastrium indicated by a square in (A). (D) A higher magnification (x200) showing hilus formations indicated by a square in $(A)$.

arrow head: red, artery; blue, veins; black, vessels; LS, lesser sac; PC, peritoneal cavity; St, stomach

Figure 5 Three-dimensional reconstruction of the spleen with the stomach at Carnegie stages 17 and 19.

Anterior, posterior, and right lateral views are shown.

Figure 6 Summary of the histological findings of the spleen (primordium) between Carnegie stages 13 and 23. 
TABLE 1. Acquisition of macroscopic findings of the spleen from Carnegie stages 13-23

\begin{tabular}{|c|c|c|c|c|c|c|c|c|c|c|c|}
\hline \multirow{2}{*}{ Findings } & \multicolumn{11}{|c|}{ Carnegie stage } \\
\hline & 13 & 14 & 15 & 16 & 17 & 18 & 19 & 20 & 21 & 22 & 23 \\
\hline \multicolumn{12}{|c|}{ Separation from the DM } \\
\hline Not recognizable & $22(100)$ & $3(20)$ & $9(43)$ & $4(7)$ & $2(7)$ & 0 & 0 & 0 & 0 & 0 & 0 \\
\hline At the bulge & 0 & $12(80)$ & $12(57)$ & $54(93)$ & $27(93)$ & 17 & 10 & 4 & 0 & 0 & 0 \\
\hline At the segment & 0 & 0 & 0 & 0 & 0 & $1(6)$ & $2(17)$ & $14(78)$ & $17(100)$ & $13(100)$ & $5(100)$ \\
\hline \multicolumn{12}{|l|}{ High density area } \\
\hline Not recognizable & $22(100)$ & $15(100)$ & $21(100)$ & $52(90)$ & $8(28)$ & 0 & 0 & 0 & 0 & 0 & 0 \\
\hline Recognizable & 0 & 0 & 0 & $6(10)$ & $21(72)$ & $18(100)$ & $12(100)$ & $18(100)$ & $17(100)$ & $13(100)$ & $5(100)$ \\
\hline Total number & 22 & 15 & 21 & 58 & 29 & 18 & 12 & 18 & 17 & 13 & 5 \\
\hline
\end{tabular}

The percentages are expressed in parentheses; DM, dorsal mesogastrium 


\section{CS14} bulging (-) bulging (+)
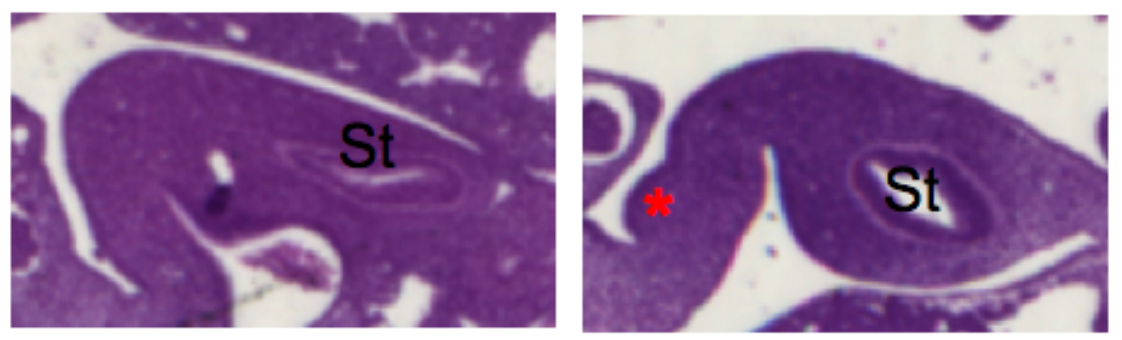

\section{CS16}

CS20
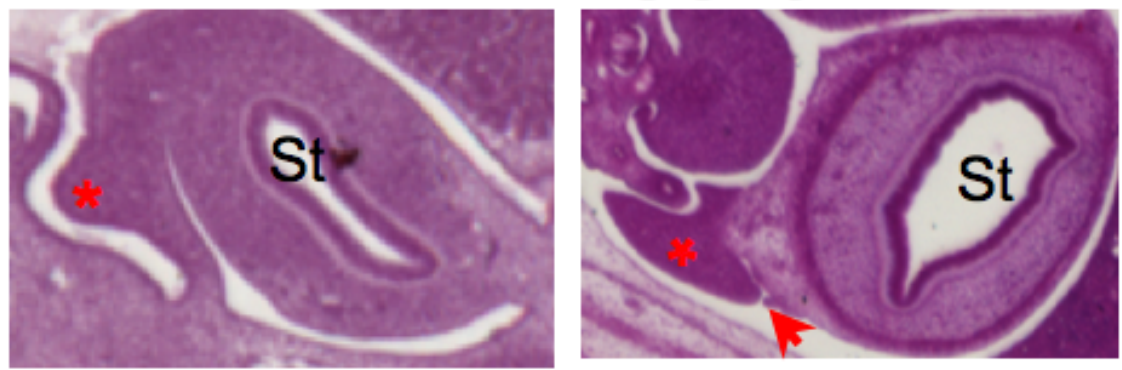

\section{CS23}

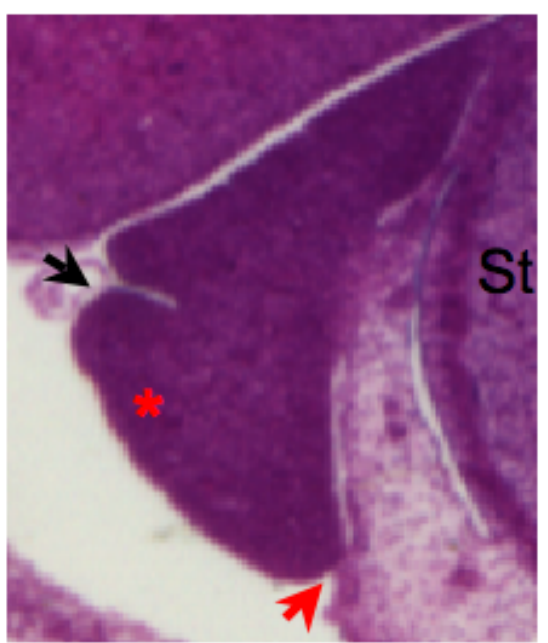




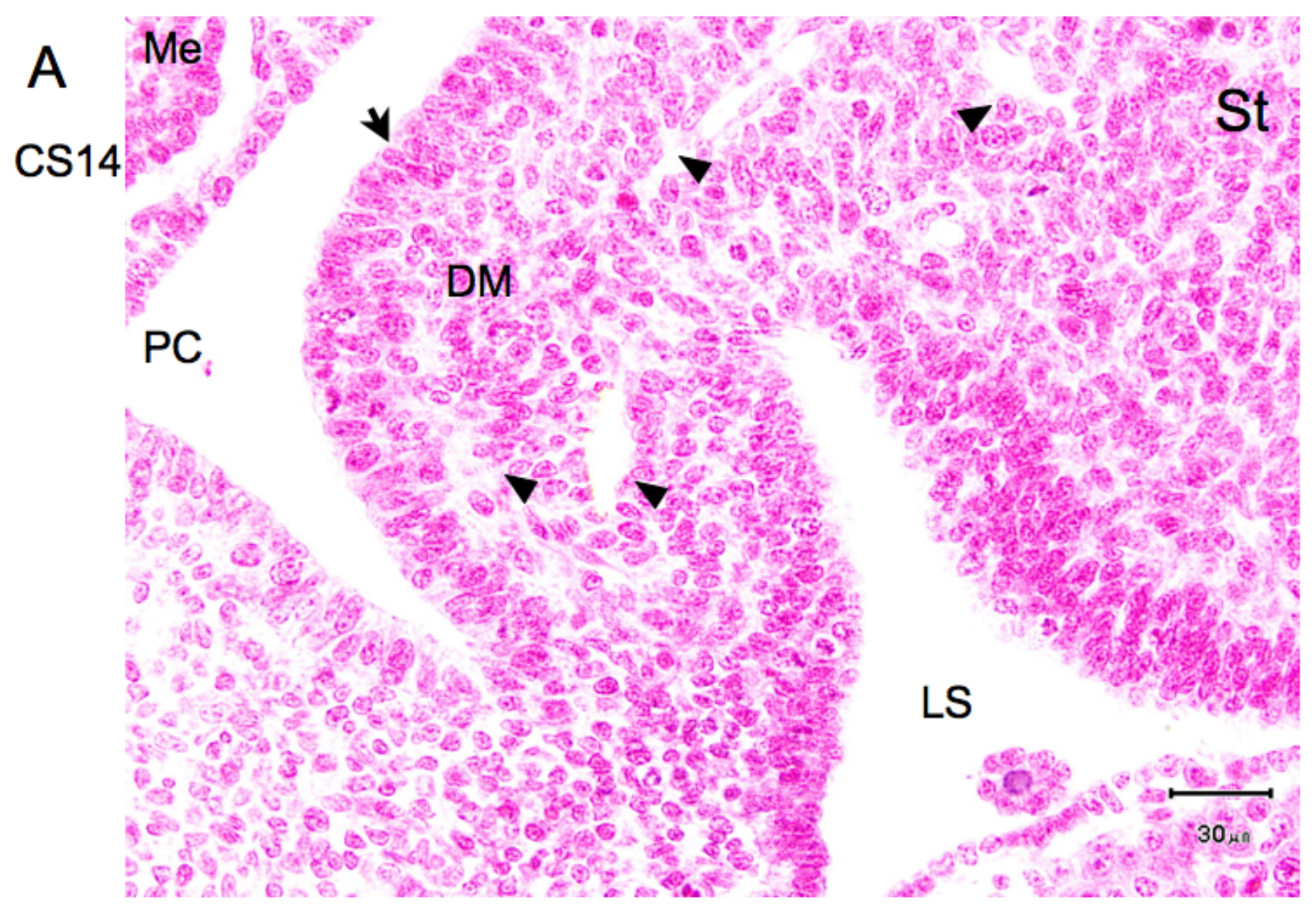

\section{B}

3yers

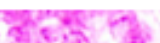 \\ $x-3$
3
3}

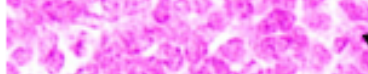

CS15

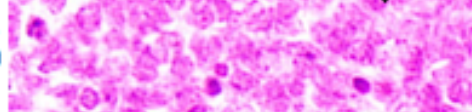

कि

P. $=0.0 \mathrm{DM}$

DM

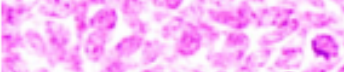

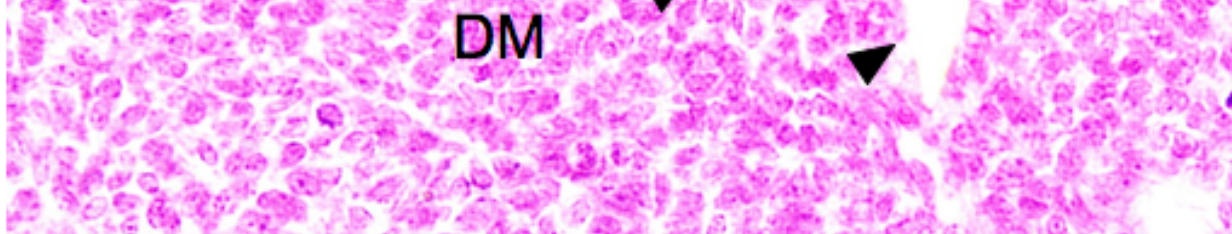

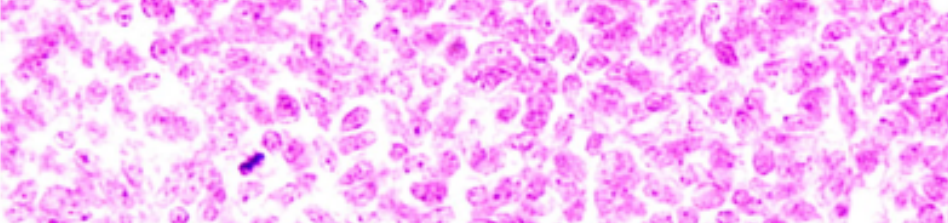

3.

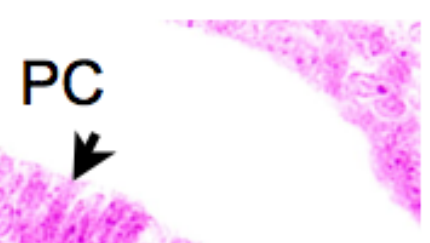

3 s.

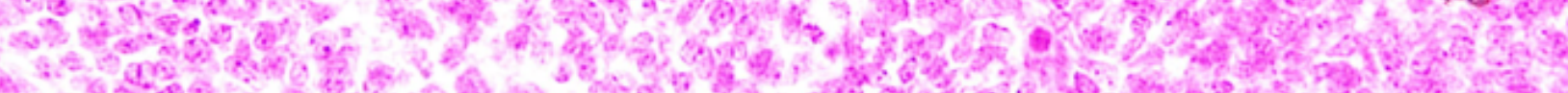

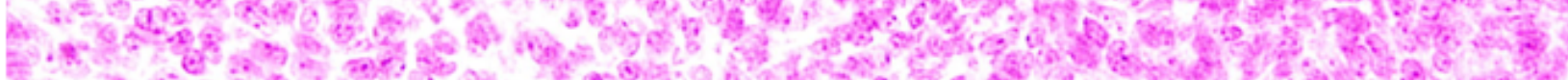

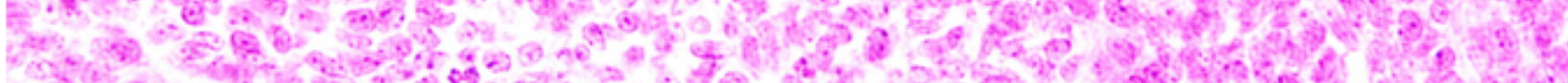

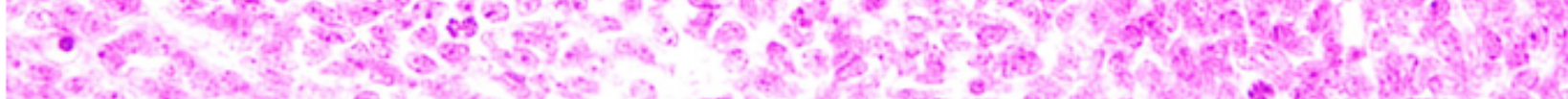

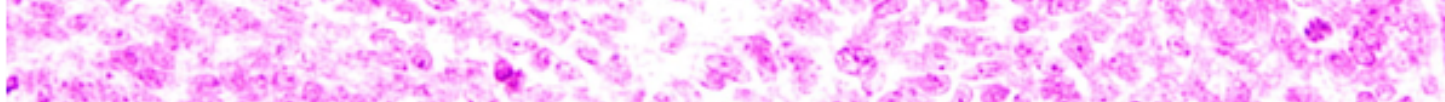

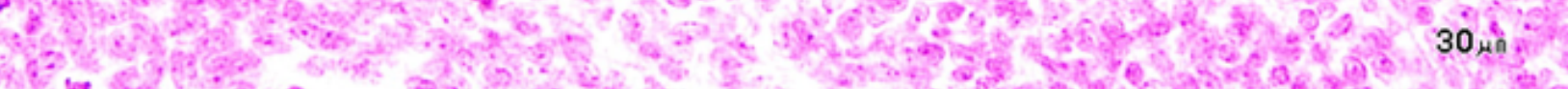

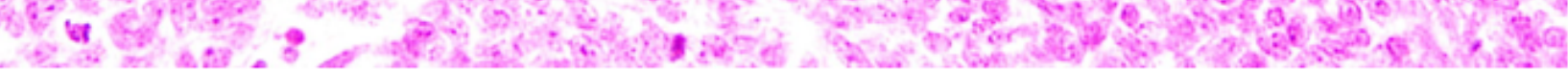



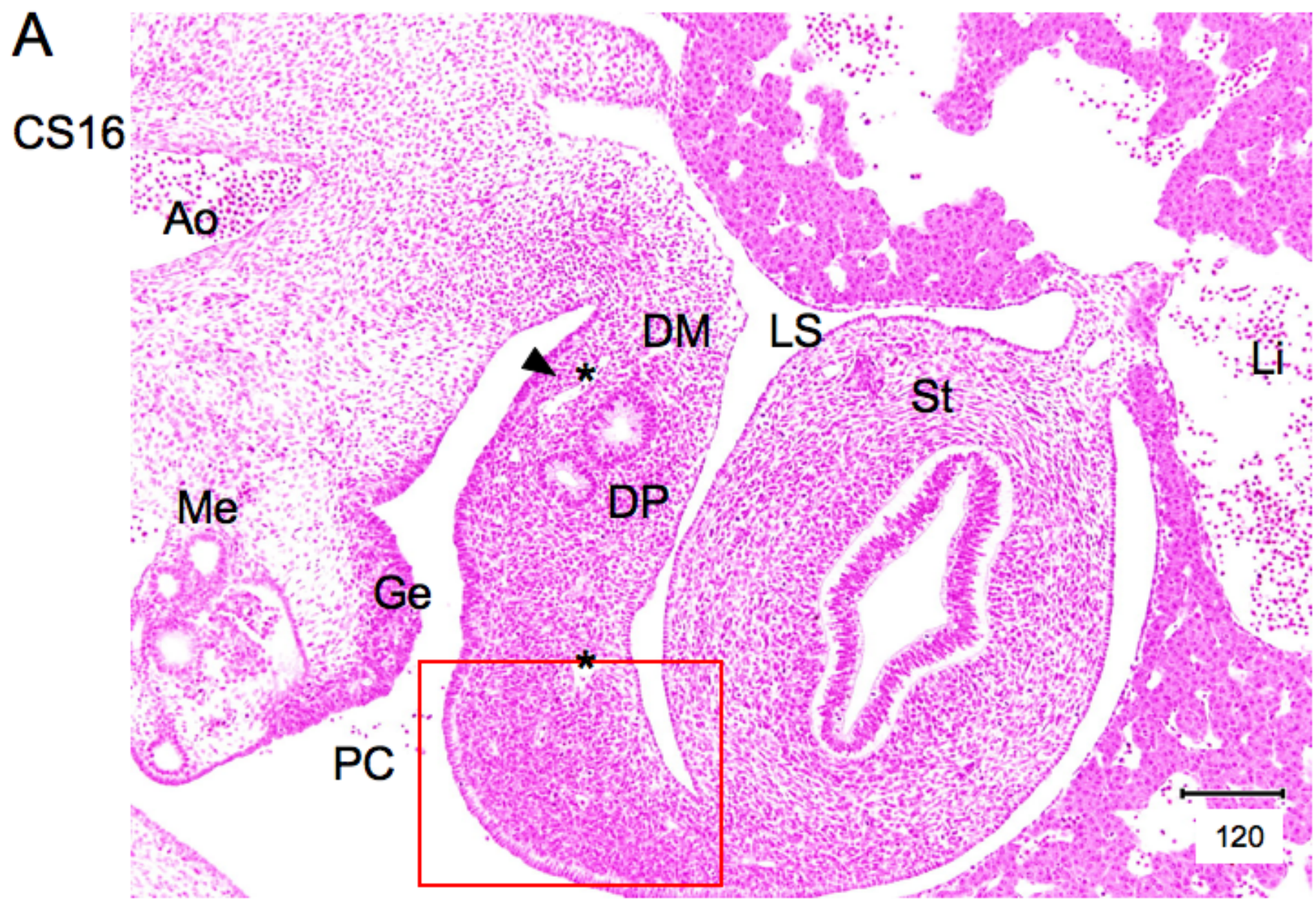

B

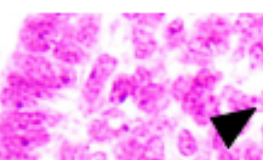

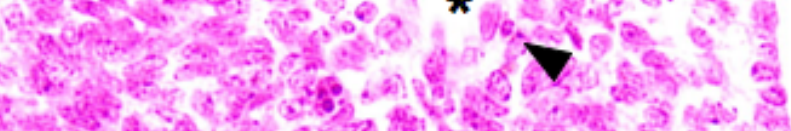

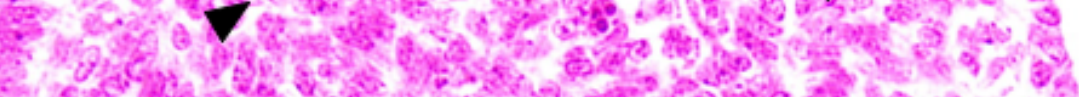

- 0

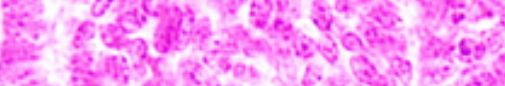

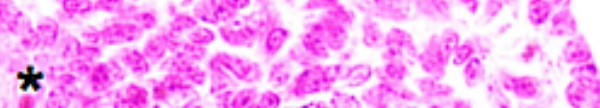

Se.

* 20 .

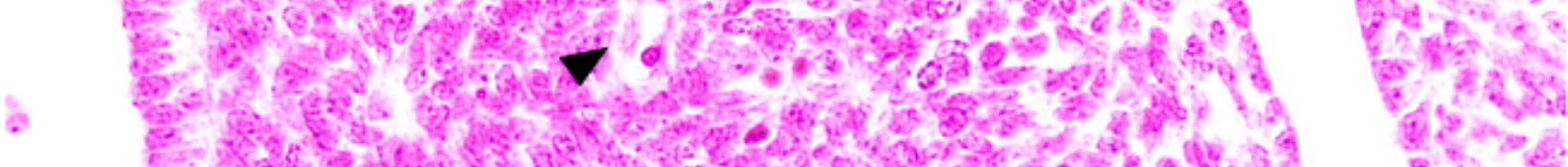

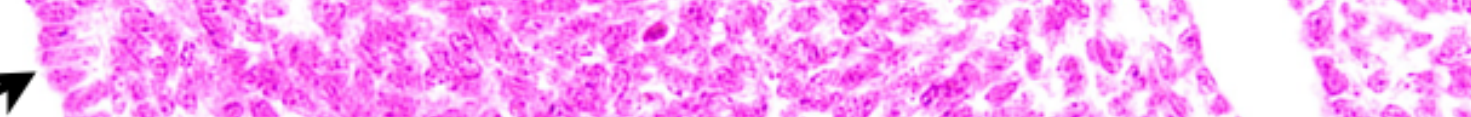

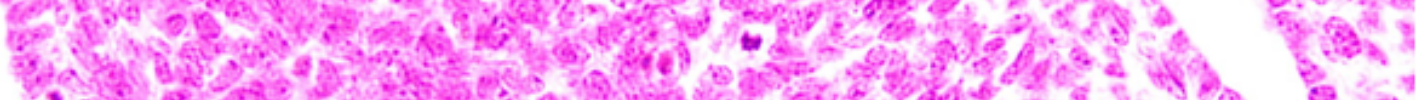
$30 \%$ \% 50 .

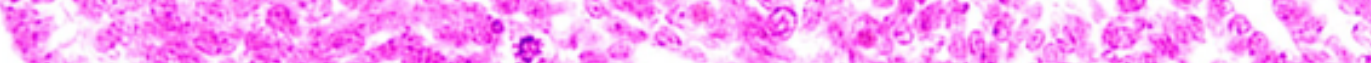

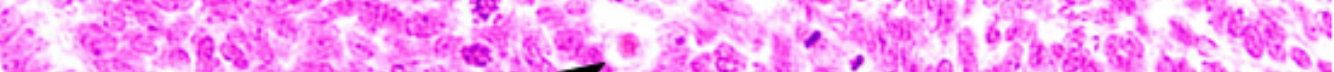

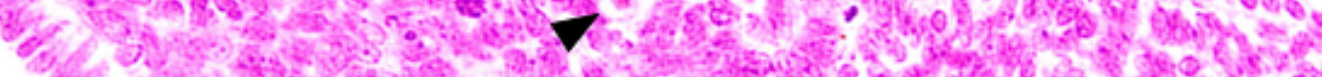

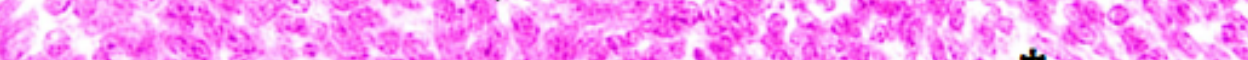

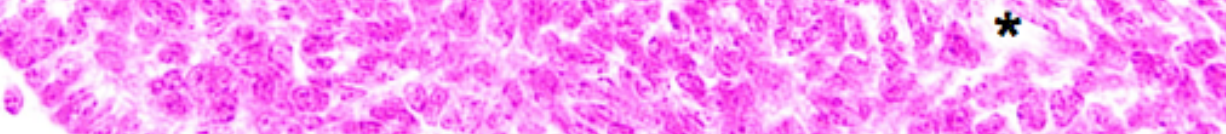

PC (5) 


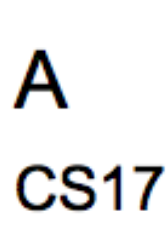

10 3.

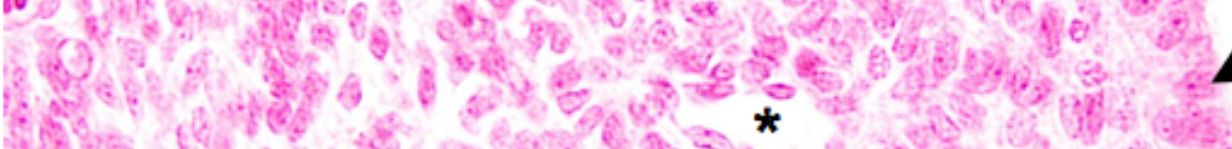

CS17

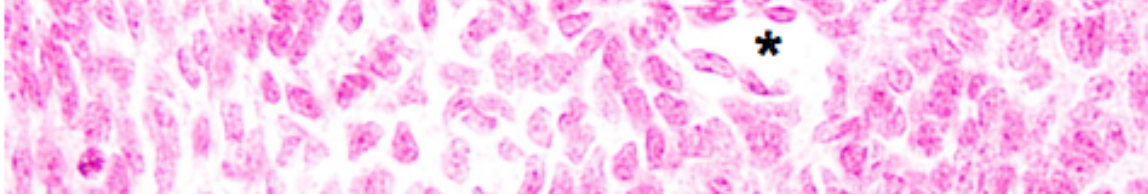

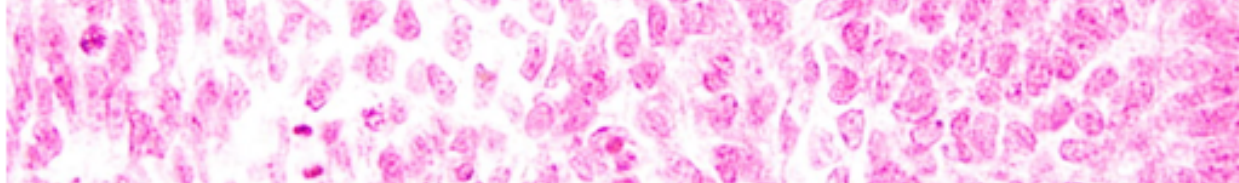
(6)

for

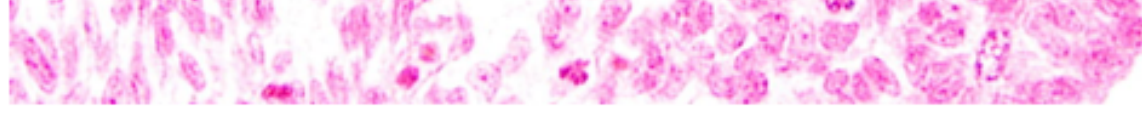

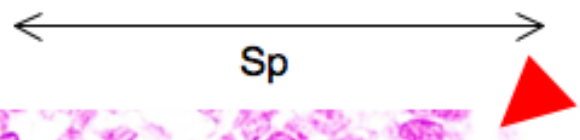

B

CS18

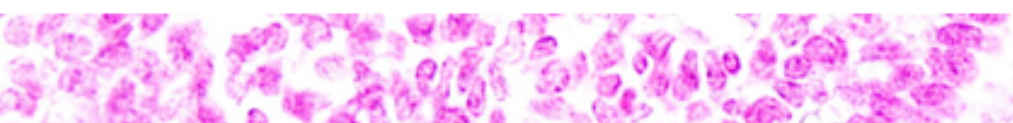

(3)

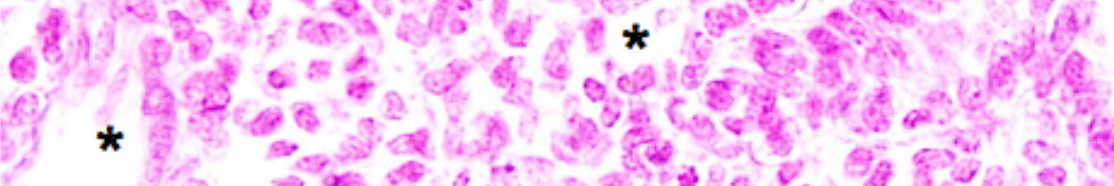

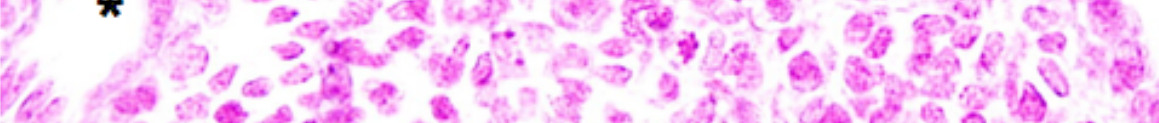

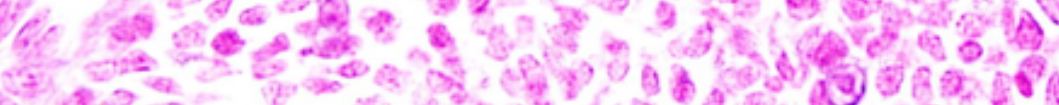

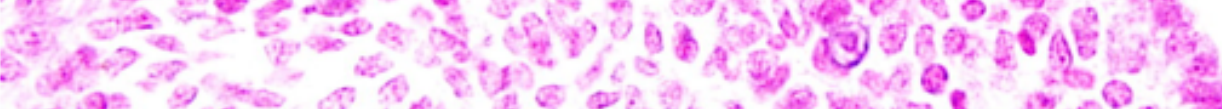

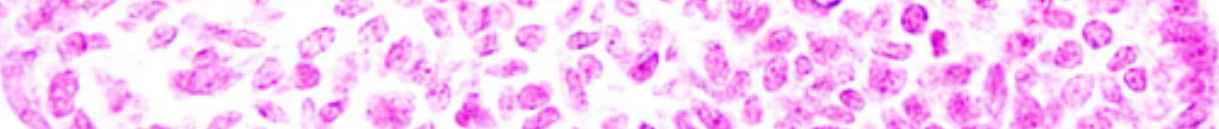

* 28 a

S2 के एक

C

CS19

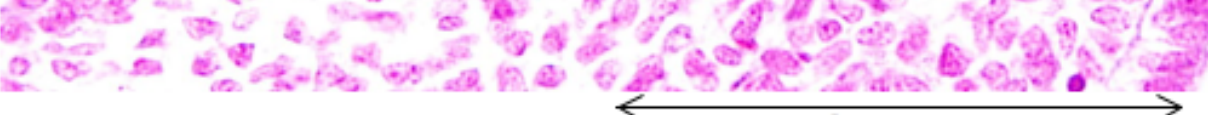

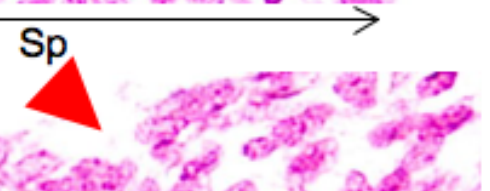

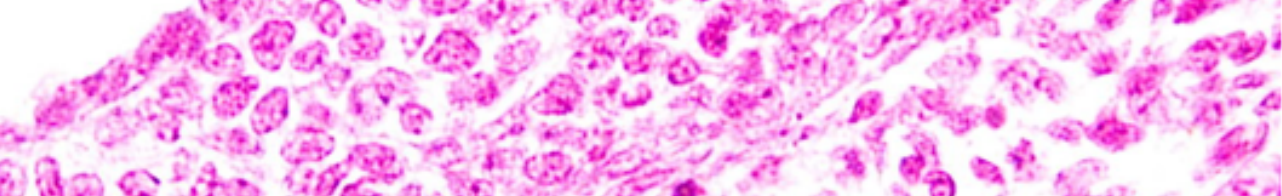
个 30 की

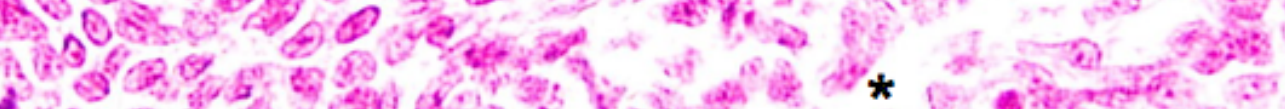

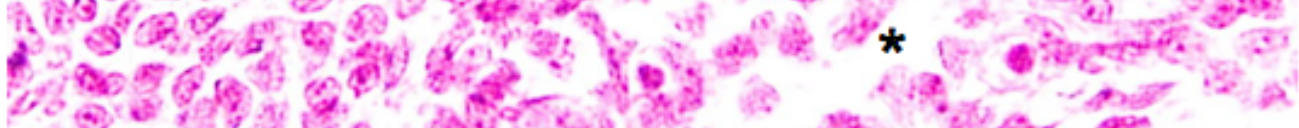

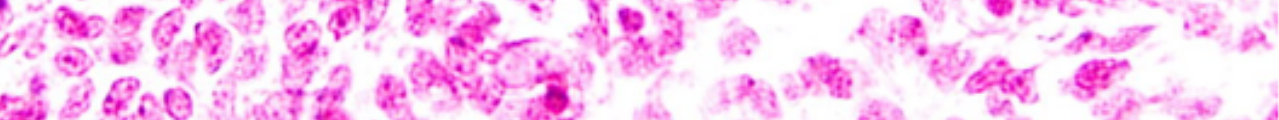

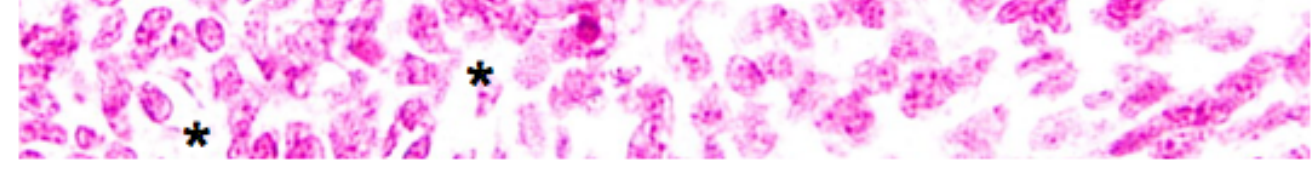


A

CS20

PC $>$ is

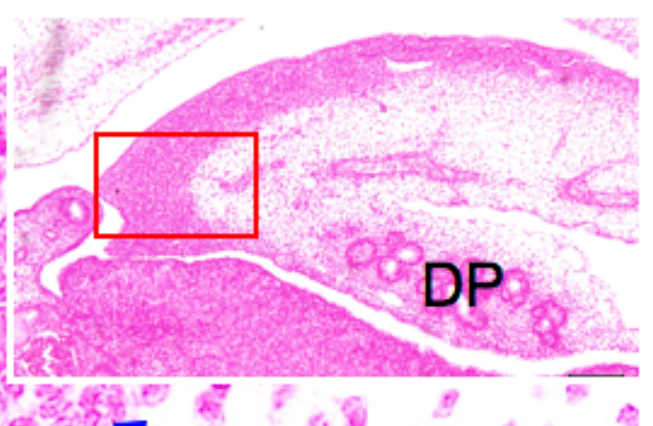

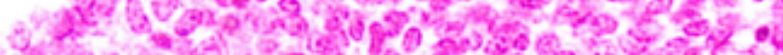

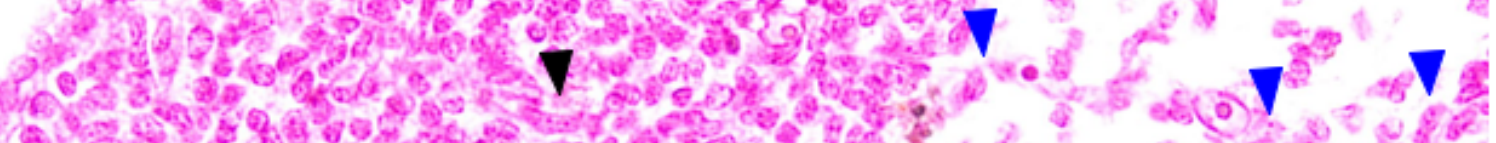

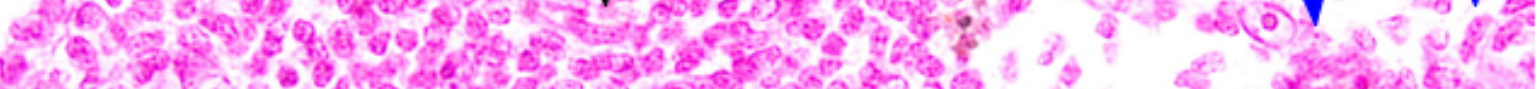

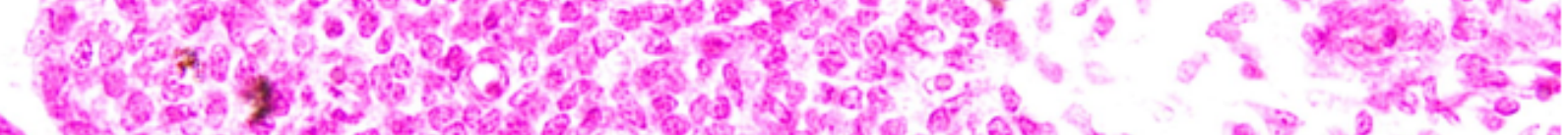

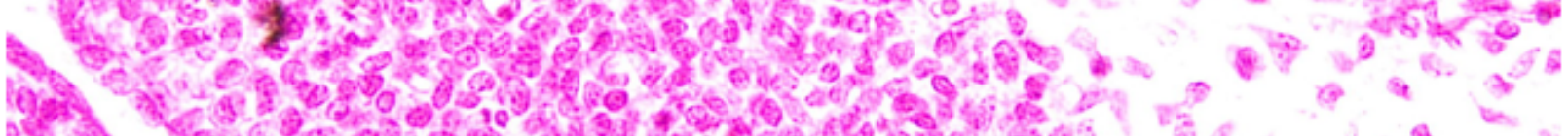
len a

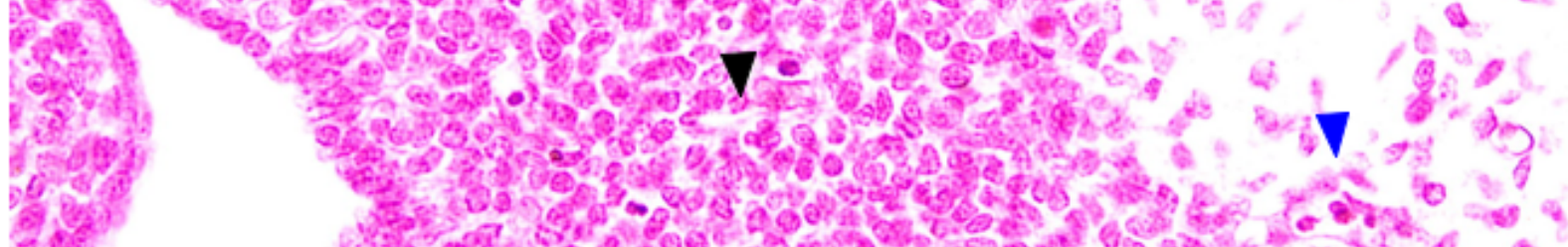
3.9.

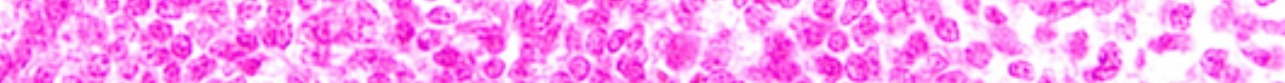

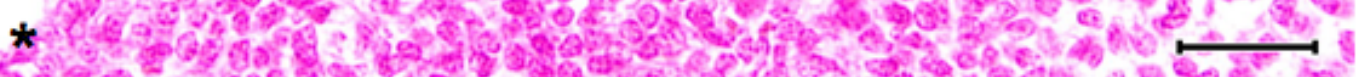

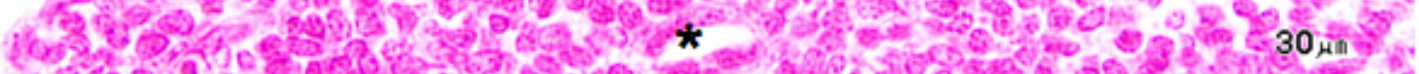

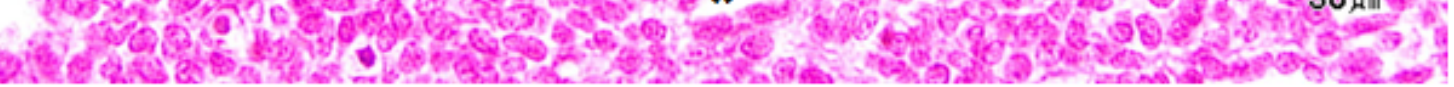

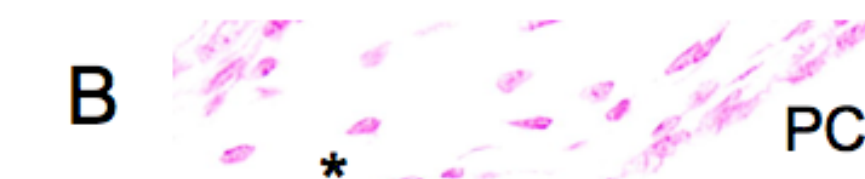

CS21

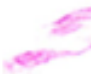

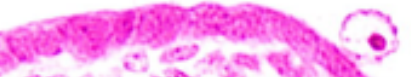

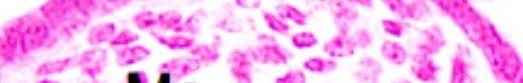

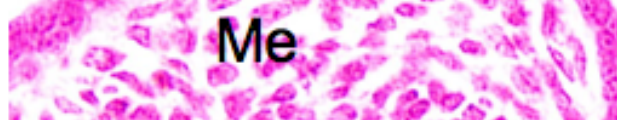

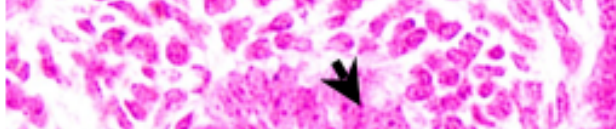

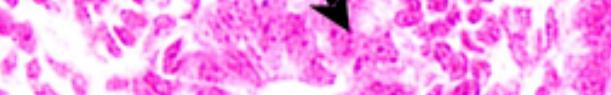

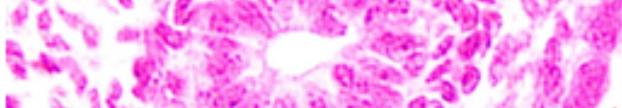

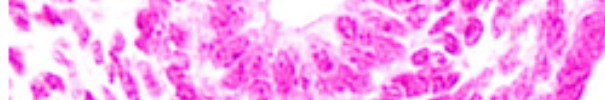

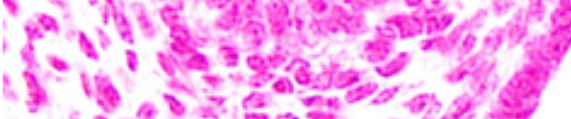

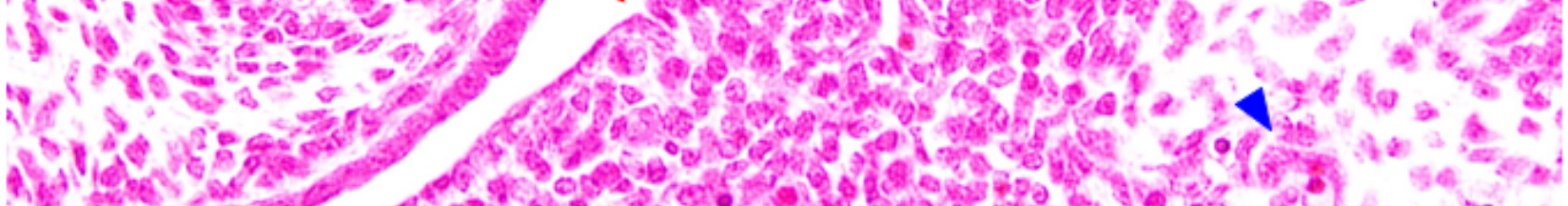
h.

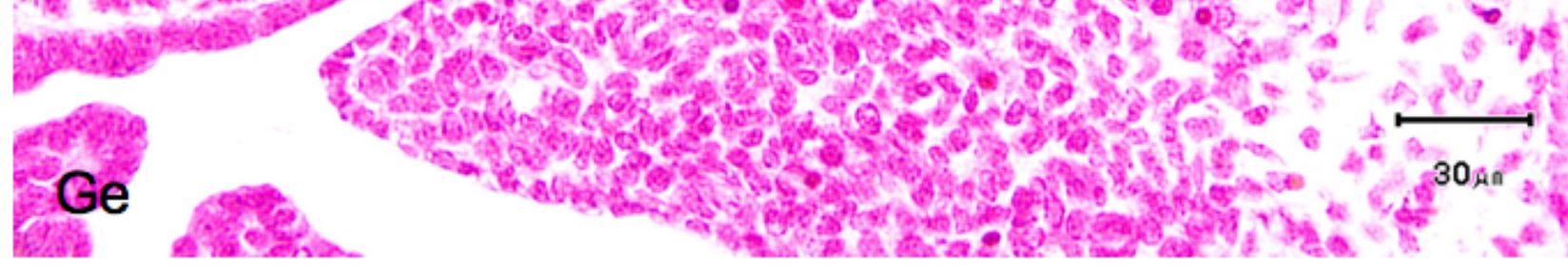



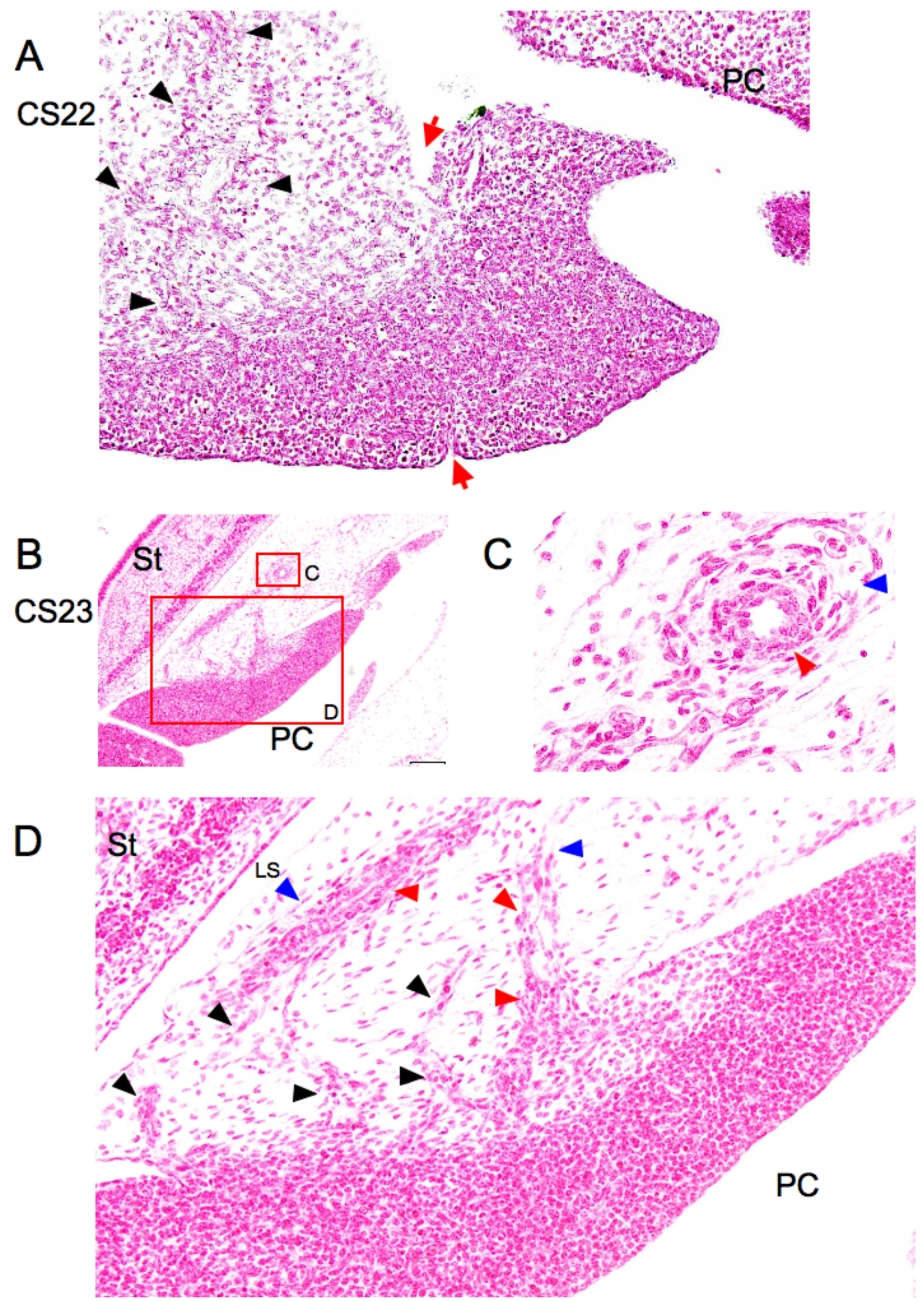
CS17

Anterior view

\section{Posterior} view

Right lateral view
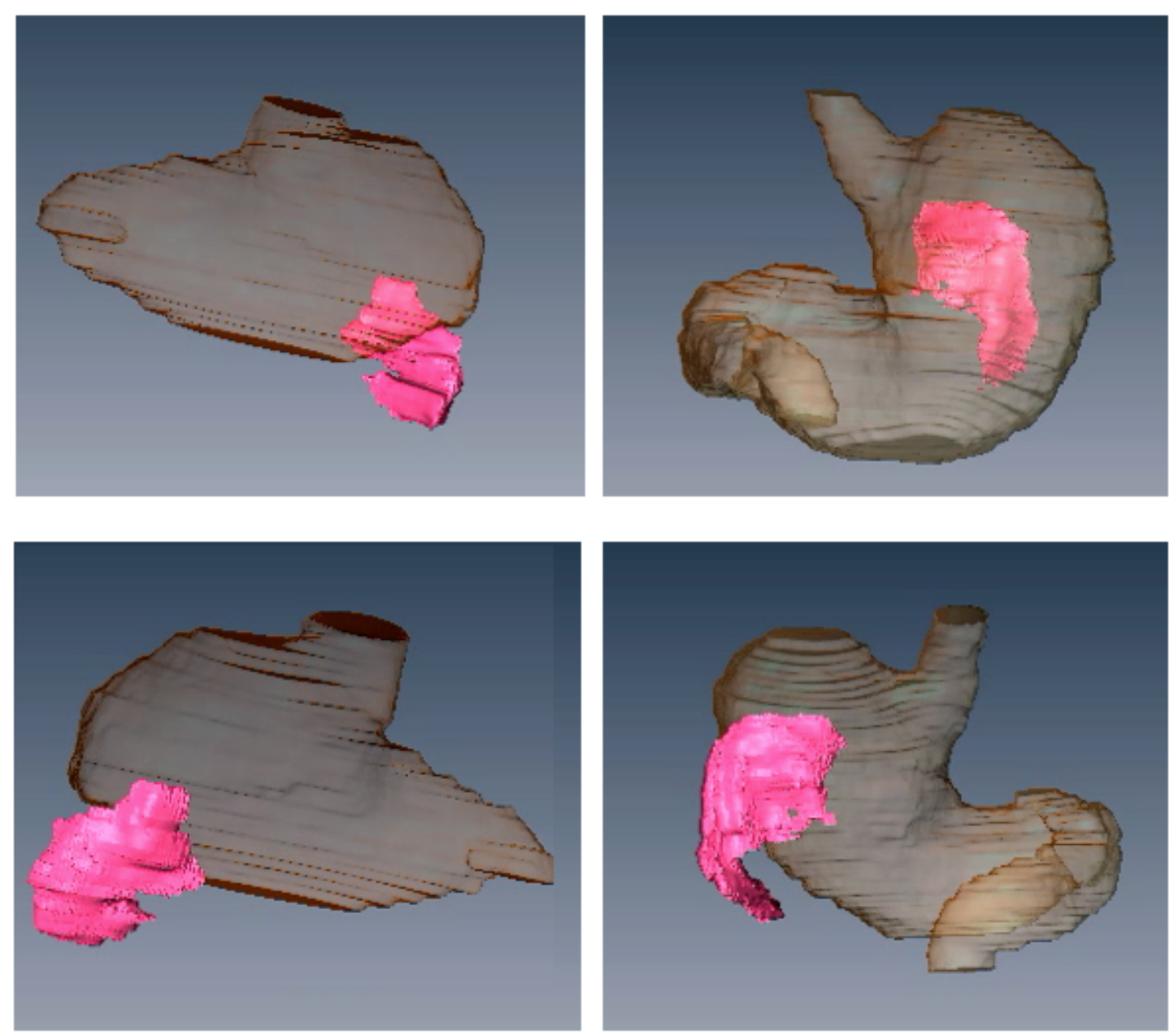

CS19

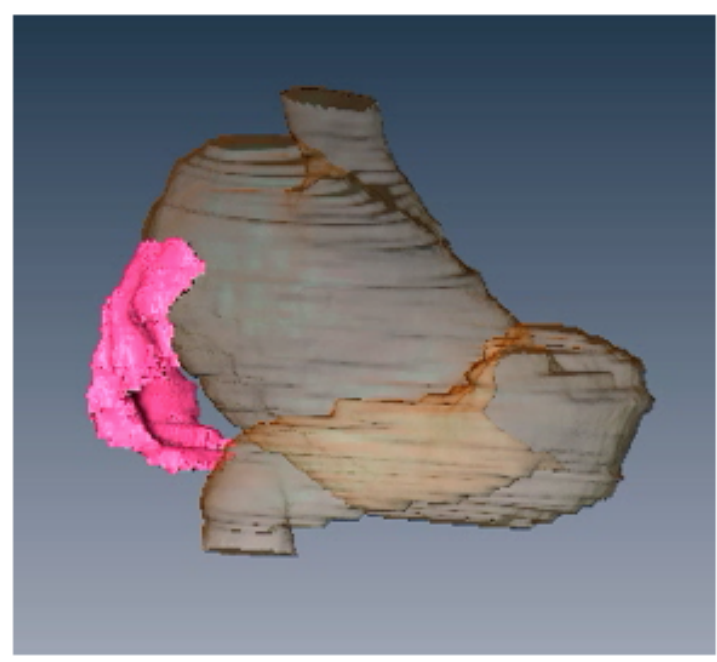




\section{$\begin{array}{llllllllllll}\text { CS } & 13 & 14 & 15 & 16 & 17 & 18 & 19 & 20 & 21 & 22 & 23\end{array}$}

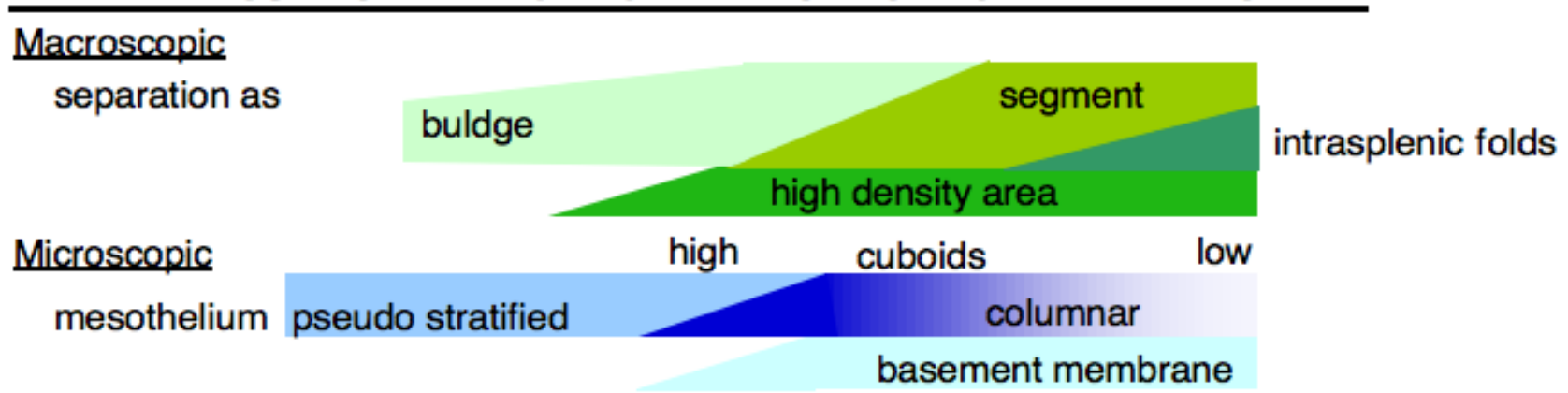
vessels
presence of the vessels in DM
hilus formation recognitions of artery, vein sinus formation
cell histology mesenchymal cells splenic mesenchymal cells hematopoietic cells 